Buletin Ilmiah Mat. Stat. dan Terapannya (Bimaster)

Volume 08, No. 2 (2019), hal $207-212$.

\title{
PENERAPAN DIAGRAM KONTROL MEWMA PADA PENGENDALIAN KARAKTERISTIK KUALITAS PENGOLAHAN AIR PDAM TIRTA KHATULISTIWA
}

\author{
Putri Catur Wahyuni, Evy Sulistianingsih, Shantika Martha \\ INTISARI
}

Pengendalian kualitas dengan diagram kontrol Multivariate Exponentially Weighted Moving Average (MEWMA), merupakan usaha untuk meminimalkan produk cacat atau rusak dari produk yang diproduksi oleh perusahaan. Hal tersebut dilakukan untuk mempertahankan kualitas produk yang dihasilkan agar sesuai dengan kriteria produk yang telah ditetapkan dan dapat diterima oleh konsumen. Dalam produksi pengolahan air bersih pada PDAM Tirta Khatulistiwa dilakukan pengontrolan kualitas dengan lima karakteristik kualitas yaitu warna, kekeruhan, suhu, Daya Hantar Listrik (DHL) dan pH dengan menggunakan Diagram Kontrol MEWMA. Penerapan diagram kontrol MEWMA pada penelitian ini menggunakan $\lambda$ senilai 0,05 dengan Batas Pengendali Atas (BPA) yaitu senilai 12,91. Proses produksi pengolahan air bersih berada di bawah batas BPA hingga pengontrolan keempat, sehingga dapat dikatakan bahwa proses telah terkontrol atau dengan kata lain proses telah stabil.

Kata Kunci: Diagram Kontrol, Multivariate Expoentially Weighted Moving Average (MEWMA), BPA

\section{PENDAHULUAN}

Pengendalian produksi akan menghasilkan efisiensi proses produksi sehingga dapat meminimalkan biaya produksi dan memberikan keuntungan yang maksimal bagi perusahaan. Kualitas produk yang selalu terjaga akan menekan biaya perbaikan dan pengembalian produk serta memberi kepuasan bagi konsumen. Untuk itu, perlu adanya pengendalian kualitas mulai dari pengendalian bahan baku, pengendalian kualitas proses hingga produk siap untuk dipasarkan. Pengendalian kualitas merupakan usaha untuk meminimalkan produk cacat atau rusak dari produk yang diproduksi oleh perusahaan [1]. Pengendalian kualitas sangat penting bagi suatu perusahaan, karena tanpa adanya pengendalian kualitas, produk akan menimbulkan kerugian bagi perusahaan [2].

Pengendalian kualitas dapat dilakukan dengan menggunakan diagram kontrol. Diagram kontrol merupakan alat untuk menggambarkan suatu karakteristik kualitas yang telah diukur dari sampel [1]. Berdasarkan peraturan Menteri Kesehatan Republik Indonesia Nomor: 492/MENKES/PER/IV/2010, air minum adalah air yang melalui proses pengolahan atau tanpa pengolahan yang memenuhi syarat kesehatan dan dapat langsung diminum. Air bersih harus memenuhi persyaratan antara lain sebagai berikut: jernih, tidak berwarna, tidak berasa, tidak berbau, tidak beracun, $\mathrm{pH}$ netral dan bebas mikroorganisme. Air yang bersih merupakan air yang harus bebas dari mikoorganisme penyebab penyakit dan bahan-bahan kimia yang dapat merugikan kesehatan manusia maupun makhluk hidup lainnya.

Diagram kontrol adalah suatu tampilan grafik untuk membandingkan data yang dihasilkan oleh proses yang sedang berlangsung saat ini terhadap suatu batasan-batasan kendali yang telah ditentukan dari data-data unjuk kerja sebelumnya [1]. Tujuan yang diharapkan dengan adanya kualitas kontrol dalam suatu proses adalah menjaga dan meningkatkan kualitas yang mempunyai efek pada penurunan biaya berkurangnya pekerjaan berulang, penurunan keterlambatan dan peningkatan penggunaan mesin [1].

Tujuan pada penelitian adalah menerapkan diagram kontrol MEWMA dalam mengendalikan karakteristik kualitas air pada Instalasi Pengolahan Air PDAM Tirta Khatulistiwa Kota Pontianak. Sehingga, penerapan pada diagram kontrol MEWMA dapat bermanfaat dalam mengontrol proses produksi pengolahan air. Penelitian ini menggunakan data bulanan pada pemeriksaan kualitas air 
minum di Instalasi Pengolahan Air PDAM Tirta Khatulistiwa Kota Pontianak, periode Januari 2014 yang paling berkontribusi terhadap hubungan yang terjadi diantara kedua kelompok variabel yang diujikan sampai Desember 2017 dengan melibatkan lima karakteristik kualitas yaitu warna, kekeruhan, suhu, DHL dan $\mathrm{pH}$.

\section{MATRIKS KOVARIANS}

Matriks sampel kovarians $\boldsymbol{S}$ adalah matriks sampel varians dan kovarians dari variabel $p$.

$$
\boldsymbol{S}=\left[\begin{array}{cccc}
s_{11} & s_{12} & \cdots & s_{1 p} \\
s_{12} & s_{22} & \cdots & s_{2 p} \\
\vdots & \vdots & \ddots & \vdots \\
s_{p 1} & s_{p 2} & \cdots & s_{p p}
\end{array}\right]
$$

Terdapat beberapa pendekatan untuk untuk memperoleh $\boldsymbol{S}$, yaitu menghitung varians sampel $s_{j j}$ dari variabel ke-j untuk $s_{j j}=s_{j}^{2}$. Perhitungan untuk $s_{j j}=s_{j}^{2}$ dengan kolom ke-j, seperti dibawah ini:

$$
s_{j j}=s_{j}^{2}=\frac{1}{n-1} \sum_{i=1}^{n}\left(y_{i j}-\bar{y}_{j}\right)^{2}
$$

dimana $\bar{y}_{j}$ adalah rata-rata dari variabel ke-j. Selanjutnya untuk kovarians sampel $s_{j k}$ dari variabel ke$j$ dan variabel ke- $k$, dihitung dengan menggunakan persamaan seperti berikut:

$$
s_{j k}=\frac{1}{n-1} \sum_{i=1}^{n}\left(y_{i j}-\bar{y}_{j}\right)\left(y_{i k}-\bar{y}_{k}\right)
$$

dimana $y_{i j}$ adalah data pada observasi ke- $i$ dan variabel ke- $j, y_{i k}$ adalah data pada observasi ke- $i$ dan variabel ke- $k$, dengan $\bar{y}_{k}$ adalah rata-rata dari variabel ke- $k[3]$.

\section{DISTRIBUSI NORMAL MULTIVARIAT}

Distribusi normal digunakan untuk mengetahui data berdistribusi normal ataukah tidak. Pengujian distribusi normal dilakukan terhadap keseluruhan variabel. Suatu vektor $\mathbf{x}=\left[\mathrm{x}_{1}, \mathrm{x}_{2}, \mathrm{x}_{3}, \ldots, \mathrm{x}_{p}\right]$ dikatakan berdistribusi normal multivariate dengan parameter $\boldsymbol{\mu}$ dan $\sum$ dengan fungsi densitas, yaitu seperti berikut:

$$
f(\mathrm{x})=\frac{1}{(2 \pi)^{\frac{p}{2}} \Sigma^{1 / 2}} e^{-\frac{1}{2}(\mathrm{x}-\boldsymbol{\mu})^{\prime} \Sigma^{-1}(\mathrm{x}-\boldsymbol{\mu})}
$$

Vektor $\mathbf{x}$ berdistribusi normal multivariat dengan p-dimensi dengan vektor mean $\boldsymbol{\mu}$ dan matriks varians kovarians $\sum$, dapat dinotasikan $\mathbf{x} \sim N_{p}\left(\boldsymbol{\mu}, \sum\right)[4]$.

Jika vektor $\mathbf{x}$ berukuran $p \times l$ berdistribusi multivariat sehingga dapat ditulis $(\mathbf{x}-\boldsymbol{\mu})^{\prime} \Sigma^{-1}(\mathbf{x}-\boldsymbol{\mu})$. Nilai $\boldsymbol{\mu}$ dan $\Sigma^{-1}$ dapat diestimasi dengan nilai $\overline{\mathbf{x}}_{. i .}$ dan $\boldsymbol{S}^{-1}$, sehingga diperoleh:

$$
d_{k j}^{2}=\left(\mathbf{x}_{k i j}-\overline{\mathbf{x}}_{i .}\right)^{T} \boldsymbol{S}^{-1}\left(\mathbf{x}_{k i j}-\overline{\mathbf{x}}_{. i .}\right)
$$

dimana $d_{k j}^{2}$ adalah jarak kuadrat pada subgrup ke- $k$ dan pengamatan ke- $j$ yang disebut juga dengan jarak Mahalanobis, $\mathbf{x}_{k i j}$ adalah vektor objek pengamatan data subgrup ke- $k$, variabel ke- $i$ dan pengamatan ke-j, $\overline{\mathbf{x}}_{i .}$. adalah vektor rata-rata variabel ke- $i$, dan $\boldsymbol{S}^{-1}$ adalah invers matriks varian kovarian [4].

Distribusi normal multivariat memiliki pemeriksaan asumsi yang dilakukan dengan hipotesis sebagai berikut:

$$
\begin{aligned}
& H_{0}=\text { Data berdistribusi normal multivariat } \\
& H_{1}=\text { Data tidak berdistribusi normal multivariat }
\end{aligned}
$$

Suatu data berdistribusi normal multivariat jika jarak Mahalanobis $d_{k j}^{2}$ terdapat kira-kira setengah atau dapat dikatakan lebih dari atau sama dengan $50 \%$ dari $d_{k j}^{2} \leq \chi_{(p, a)}^{2}$ [4].

DIAGRAM KONTROL MULTIVARIATE WEIGHTED MOVING AVERAGE (MEWMA)

Diagram kontrol Multivariate Exponentially Weighted Moving Average (MEWMA) merupakan 
salah satu teknik utama pada proses pengendalian kualitas statistik yang digunakan untuk mengurangi cacat dalam proses, dengan variabel karakteristik kualitas yang diperiksa lebih dari satu yaitu disebut juga dengan multivariat [2]. Diagram Kontrol MEWMA terdiri dari beberapa proses yaitu menghitung rata-rata terbobot semua rataan sampel MEWMA $\boldsymbol{Z}_{j}$ yang akan dijelaskan pada persamaan di bawah ini:

$$
\boldsymbol{Z}_{j}=\lambda \boldsymbol{X}_{j}+(1-\lambda) \boldsymbol{Z}_{j-1}
$$

dimana $\boldsymbol{Z}_{0}=0$, dengan $j$ merupakan banyaknya pengamatan yang dilakukan $(j=1,2,3, \ldots, t)$ dan $\lambda$ merupakan nilai pembobot, dengan $0<\lambda<1$. Sedangkan untuk $\boldsymbol{X}_{j}$ adalah vektor karakteristik mutu yang diamati [4].

Sebelum menghiung $\boldsymbol{Z}_{j}$ terlebih dahulu dilakukan proses standarisasi data $\boldsymbol{X}_{j}$, dengan menggunakan persamaan berikut:

$$
Z_{k i j}=\frac{X_{k i j}-\mu_{i}}{\sigma_{i}}
$$

dengan $X_{k i j}$ adalah pengamatan ke-j $(j=1,2,3, \ldots, t)$ untuk variabel ke- $i(i=1,2,3, \ldots, p)$ pada subgrup ke- $k(k=1,2,3, \ldots, m)$ dan $\sigma_{i}$ merupakan standar deviasi untuk variabel ke- $i$. Selanjutnya perhitungan titik pengamatan pada diagram kontrol MEWMA akan dijelaskan pada persaaman di bawah ini [4].

$$
M_{j}=Z_{j}^{T} \boldsymbol{S}_{Z_{j}}^{-1} \boldsymbol{Z}_{j}
$$

dimana

$$
\boldsymbol{S}_{Z_{j}}=\frac{\lambda}{2-\lambda}\left[1-(1-\lambda)^{2 j}\right] \boldsymbol{S}_{t}
$$

$\boldsymbol{S}_{t}$ adalah matriks varian kovarian dari data

Dagram kendali memiliki Batas Pengendali Atas (BPA) dan Batas Pengendali Bawah (BPB). BPB untuk diagram kontrol MEWMA adalah 0, sedangkan untuk BPA diperoleh berdasarkan Tabel MEWMA sesuai dengan nilai $\lambda$ yang ditentukan. Pembuatan diagram kontrol MEWMA dengan cara membuat plot-plot $M_{j}$. Proses dikatakan tidak terkendali apabila terdapat $M_{j}>B P A$ dan proses terkendali jika $M_{j}<B P A[4]$.

\section{PENERAPAN DIAGRAM KONTROL MEWMA}

Diagram kontrol MEWMA digunakan untuk pengendalian karakteristik kualitas air bersih pada Instalasi Pengolahan Air bersih. Data yang digunakan adalah data sekunder berupa data kunantitatif yang meliputi lima parameter yaitu warna, kekeruhan, suhu, DHL dan pH dalam air di kota Pontianak pada bulan Januari 2014 hingga Desember 2017.

Pada tahapan ini dilakukan pemeriksaan asumsi distribusi normal multivariat pada data dengan menggunkan Jarak Mahalanobis, dengan hipotesis:

$H_{0}$ : Data kualitas air berdistribusi normal multivariat

$H_{1}$ : Data kualitas air tidak berdistribusi normal multivarat.

Berdasarkan hasil uji asumsi normal multivariat diperoleh nilai $d_{k j}^{2}$ yang kurang dari nilai tabel $\chi_{(5: 0,5)}^{2}=4,35$ yang berjumlah 29 dari 48 sampel data. Dengan kata lain terdapat statistik uji $d_{k j}^{2} \geq$ $50 \%$ sehingga $H_{0}$ gagal ditolak, yang berarti data produksi kualitas air mengikuti distribusi normal.

Sebelum menghitung nilai $\boldsymbol{Z}_{j}$, terlebih dahulu dilakukan standarisasi data dengan menggunakan persamaan (2). Selanjutnya barulah dihitung $\boldsymbol{Z}_{j}$ berdasarkan persamaan (1), diperoleh nilai $\boldsymbol{Z}_{j}$ seperti berikut:

$$
\boldsymbol{Z}_{1}=\lambda \mathbf{x}_{\mathbf{1}}+(1-\lambda) \boldsymbol{Z}_{0} \text {, dengan } \boldsymbol{Z}_{0}=0
$$




$$
\boldsymbol{Z}_{1}=0,05\left[\begin{array}{c}
-0,0748 \\
-0,4297 \\
0,0942 \\
0,2863 \\
-0,3479
\end{array}\right]+(1-0,05) 0=\left[\begin{array}{c}
-0,0037 \\
-0,0215 \\
0,0047 \\
0,0143 \\
-0,0174
\end{array}\right]
$$

Sehingga didapat nilai $\boldsymbol{Z}_{2}$ pada periode kedua, sebagai berikut:

$$
\begin{aligned}
\boldsymbol{Z}_{2} & =\lambda \mathbf{x}_{2}+(1-\lambda) \boldsymbol{Z}_{1} \\
\boldsymbol{Z}_{2} & =0,05\left[\begin{array}{c}
0,2244 \\
0,3319 \\
0,1708 \\
-0,0240 \\
-1,1925
\end{array}\right]+(1-0,05)\left[\begin{array}{c}
-0,0037 \\
-0,0215 \\
0,0047 \\
0,0143 \\
-0,0174
\end{array}\right]=\left[\begin{array}{c}
0,0077 \\
-0,0038 \\
0,0130 \\
0,0124 \\
-0,0761
\end{array}\right]
\end{aligned}
$$

Kemudian dicari nilai matriks varians kovarians dari $\boldsymbol{Z}_{j}$ dengan menggunakan persamaan (4), namun terlebih dahulu dicari nilai matriks varian-kovarian dari data yang telah distandarisasi dengan menggunakan persamaan 5 dan persamaan 6 , sehingga mariks varians kovarians dari $\boldsymbol{Z}_{j}$ misalnya untuk pengamatan pertama diperoleh

$$
\begin{aligned}
\boldsymbol{S}_{\boldsymbol{Z}_{1}} & =\frac{\lambda}{2-\lambda}\left[1-(1-\lambda)^{2.1}\right] \boldsymbol{S}_{t} \\
\boldsymbol{S}_{\boldsymbol{Z}_{1}} & =\left[\begin{array}{ccccc}
0,0025 & 0,0005 & 0,0006 & -0,0004 & 0,0000 \\
0,0005 & 0,0025 & 0,0001 & 0,0006 & -0,0010 \\
0,0006 & 0,0001 & 0,0025 & -0,0003 & 0,0000 \\
-0,0004 & 0,0006 & -0,0003 & 0,0025 & 0,0003 \\
0,0000 & -0,0010 & 0,0000 & 0,0003 & 0,0025
\end{array}\right]
\end{aligned}
$$

karena matrikas $\boldsymbol{Z}_{j}$ dan matriks varians kovarians dari $\boldsymbol{Z}_{j}\left(\boldsymbol{S}_{\boldsymbol{Z}_{j}}\right)$ telah diperoleh, sehingga untuk titik pengamatan $M_{j}$ dapat dihitung dengan menggunakan persamaan (3), maka titik pengamatan pertama yang diperoleh

$$
\begin{aligned}
M_{1}= & Z_{1}{ }^{T} \boldsymbol{S}_{Z_{1}}{ }^{-1} \boldsymbol{Z}_{\mathbf{1}} \\
M_{1}= & {\left[\begin{array}{cccccc}
-0,0037 & -0,0215 & 0,0047 & 0,0143 & -0,0174
\end{array}\right] } \\
& {\left[\begin{array}{ccccc}
463,1265 & -137,9795 & -75,7884 & 105,5222 & -65,5883 \\
-137,9795 & 568,0042 & -13,6292 & -184,5797 & 246,8878 \\
-85,7884 & -13,6292 & 423,4844 & 35,5881 & -12,8212 \\
105,5222 & -184,5797 & 35,5881 & 479,2222 & -130,99 \\
-65,5883 & 246,8878 & -12,8212 & -130,9995 & 513,4861
\end{array}\right]\left[\begin{array}{c}
-0,0037 \\
-0,0215 \\
0,0047 \\
0,0143 \\
-0,0174
\end{array}\right] } \\
M_{1}= & 0,8656
\end{aligned}
$$

Lakukan hal yang sama seperti pada $M_{1}$ hingga titik pengamatan yang ke-48.

Batas pengendali Atas (BPA) pada tabel MEWMA dengan $\lambda=0,05$ dan $p=5$, sehingga $\mathrm{BPA}=12,91$. Karena BPA telah diperoleh, maka diagram kontrol MEWMA dapat ditunjukkan seperti Gambar 1.

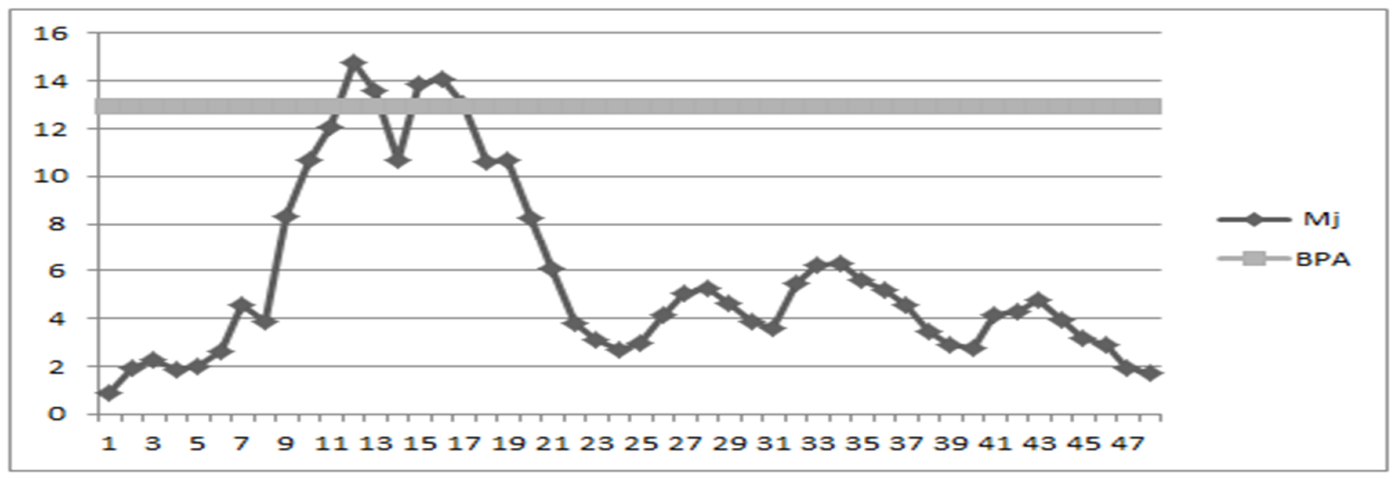

Gambar 1. Diagram Kontrol MEWMA Karakteristik Pengolahan Air PDAM Tirta Khatulistiwa Pontianak Pengontrolan Pertama 
Berdasarkan Gambar 1, dari 48 titik pengamatan dapat diketahui bahwa terdapat 5 pengamatan yang keluar melebihi dari batas kontrol MEWMA yaitu pada pengamatan ke 12, 13, 15, 16 dan 17. Setelah faktor penyebab proses tidak terkontrol diketahui, maka kelima pengamatan dikeluarkan dan dilakukan pengontrolan kembali dengan asumsi tidak terdapat gangguan dalam proses produksi. Pengontrolan dilakukan sebanyak empat kali, pengontrolan yang keempat adalah proses yang telah terkontrol karena tidak terdapat $M_{j}$ yang keluar dari batas kontrol. Diagram kontrol proses pengolahan air PDAM Khatulistiwa Pontianak pada pengontrolan keempat sudah memenuhi proses, yang ditunjukkan pada Gambar 2.

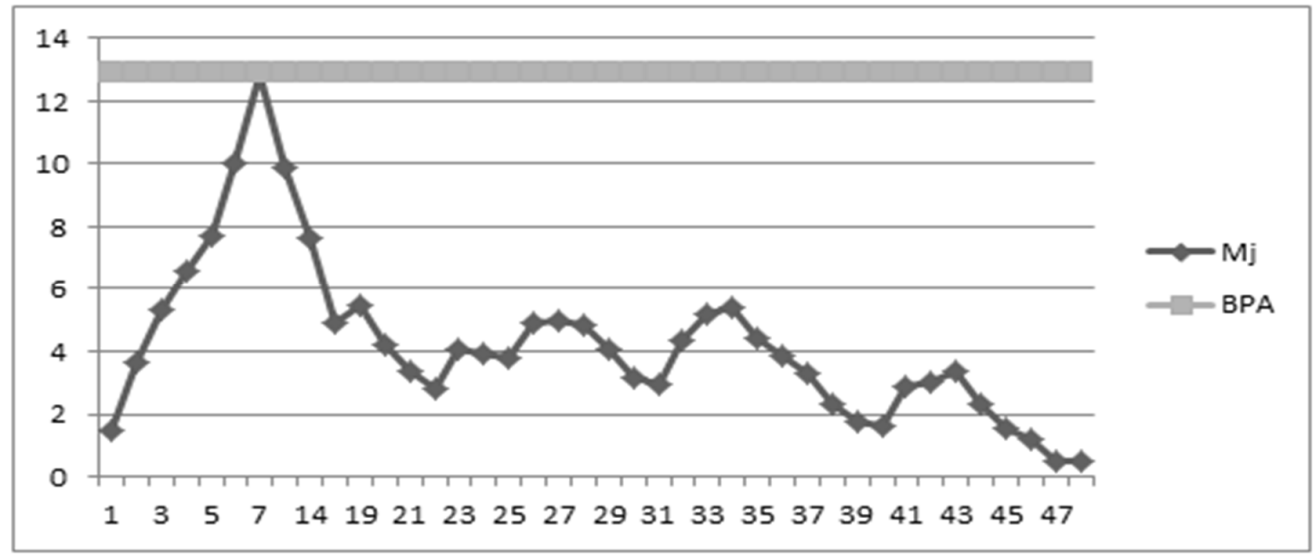

Gambar 2. Diagram Kontrol MEWMA Karakteristik Pengolahan Air PDAM Tirta Khatulistiwa Pontianak Pengontrolan Keempat.

Pengamatan yang tidak terkontrol (out of control) pada pengontrolan pertama hingga pengontrolan keempat dikeluarkan dalam proses pengontrolan selanjutnya. Berikut adalah pengamatan yang tidak terkontrol pada diagram MEWMA.

Tabel 1. Titik Pengamatan $M_{j}$ Tidak Terkontrol

\begin{tabular}{ccc}
\hline $\begin{array}{c}\text { Pengontrol } \\
\text { an ke- }\end{array}$ & $\begin{array}{c}\text { Jumlah } \\
\text { Pengamatan Tidak } \\
\text { Terkontrol }\end{array}$ & $\begin{array}{l}\text { Pengamatan } \\
\text { yang } \\
\text { Terkontrol }\end{array}$ \\
\hline 1 & 5 & Tidak \\
2 & 2 & $12,13,15,16,17$ \\
3 & 1 & 9,11 \\
4 & 0 & - \\
\hline
\end{tabular}

Berdasarkan Gambar 2 dan Tabel 1 dapat diketahui bahwa variabilitas dari proses pengolahan sudah terkontrol pada pengontrolan keempat. Hal ini ditunjukan dengan titik adanya pengamatan yang keluar melebihi BPA dan nilai kontrol BPB yaitu nol. Sehingga, dapat dikatakan bahwa proses pengolahan air PDAM Tirta Khatulistiwa telah stabil.

\section{PENUTUP}

Berdasarkan hasil analisis penerapan diagram kontrol MEWMA, diperoleh kesimpulan bahwa pada data karakteristik kualtas air di Instalasi Pengolahan Air PDAM Tirta Khatulistiwa Kota Pontianak, dengan karakteristik kualitas yaitu warna, kekeruhan, suhu, DHL dan $\mathrm{pH}$ pada air bersih, 
periode Januari 2014 hingga Desember 2017 menunjukkan bahwa proses terkendali secara statistik dengan melakukan empat pengontrolan pada diagram MEWMA. Dengan kata lain, proses produksi air bersih sudah terkontrol. Sehingga, dapat dikatakan bahwa proses produksi kualitas air pada Instalasi Pengolahan Air PDAM Tirta Khatulistiwa Kota Pontianak telah stabil.

\section{DAFTAR PUSTAKA}

[1]. Montgomery, DC. Pengantar Pengendalian Kualitas Statistik [Soejoeti, Zanzawi]. Yogyakarta; Universitas Gajah Mada; 1990.

[2]. Arinda, Anastasia. Penerapan Diagram Kontrol Mutivariat Exponentially Weight Moving Average (MEWMA) Pada Pengendalian Karakteristik Kualitas Air. Semarang: Lembaga Penerbit Jurusan Statistika FSM Universitas Diponegoro; 2016 (31-33).

[3]. Rencher, AC. Metods of Multivariate Analysis. Canada: Jhon Wiley and Sons; 2002.

[4]. Jhonson, RA and Winchern, DW. 1998. Applied Multivariate Statistical Analysis Fourth Edition. Amerika: Pearson Prentice Hall.

[5]. Montgomery, DC. Statistical Quality Control, Seventh Edition. New York: JhonWiley and Sons; 2009.

PUTRI CATUR WAHYUNI : Jurusan Matematika FMIPA UNTAN, Pontianak putricatur.wahyuni@student.untan.ac.id

EVY SULISTIANINGSIH : Jurusan Matematika FMIPA UNTAN, Pontianak evysulistianingsih@math.untan.ac.id

SHANTIKA MARTHA : Jurusan Matematika FMIPA UNTAN, Pontianak shantika.martha@math.untan.ac.id 